DOI: 10.17805/zpu.2017.2.5

\title{
Неустойчивый баланс между коллективным и индивидуальным началами в культуре. Свобода как индикатор равновесия
}

\author{
А. Я. ФЛИЕР
}

РОССИЙСКИЙ НАУЧНО-ИССЛЕДОВАТЕЛЬСКИЙ ИНСТИТУТ

КУЛЬТУРНОГО И ПРИРОДНОГО НАСЛЕДИЯ ИМ. Д. С. ЛИХАЧЕВА

Статья посвящена рассмотрению взаимодействия и баланса коллективной и индивидуальной форм жизнедеятельности и соответствующих культур, исторических тенденций этого процесса и его связанности со становлением и развитием представлений о свободе, с доминантными формами идеологии.

Обосновывается единство целей социального и символического сегментов культуры по обеспечению социальной интеграции, как непосредственного, так и опосредованного. 
Изначально культура была сосредоточена на апологии коллективного начала в жизнедеятельности. «Реабилитация» индивидуального начала в культуре начинается с искусства итальянского Ренессанса. В социальной жизни процесс индивидуализации начался с возникновения дуэли как акции по защите личного достоинства и системы идентификации человека по имени и фамилии. Современная эпоха отличается высоким уровнем развития индивидуальной культуры и сокращением сферы коллективной культуры.

Но речь не идет о вытеснении одного другим, а только о балансе обоих начал. Этот баланс выражается в масштабе свободы. Свобода и есть выражение актуального психологически комфортного баланса коллективного и индивидуального начал в культуре. Расширение свободы - это усиление индивидуального начала. Наглядней всего этот баланс выражен в господствующей идеологии. Этот баланс исторически неустойчив и связан с преобладанием того или иного социально-политического сегмента в обществе. Но в любом случае общество нуждается в поддержании психологически комфортного соотношения между коллективной и индивидуальной культурами.

Ключевые слова: культура; свобода; коллективная культура; индивидуальная культура; идеология; специализация

\section{ВВЕАЕНИЕ}

$\mathrm{C}$ татья посвящается исследованию параметров взаимодействия между системами коллективной и индивидуальной культур, анализу исторической динамики соотношения этих систем и их роли в регуляции социальной жизни общества.

В ходе истории человеческого общества наблюдается нарастание распространенности и значимости форм индивидуальной культуры при одновременной локализации форм коллективной культуры. С чем это связано? В статье дается авторское истолкование причин этого процесса, имеющего выраженные исторические последствия, воплощенные в расширении границ социальной свободы людей.

Цель этой статьи заключается в анализе параметров взаимодействия между коллективной и индивидуальной культурами и осмыслению процесса постепенной индивидуализации культуры, что в конечном счете ведет к расширению границ социальной свободы.

\section{ПРОЦЕСС ИНАИВИАУААИЗАЦИИ КУАЬТУРЫ: ИСТОРИЧЕСКИЕ ПРИМЕРЫ}

Трудно рассуждать о культуре «вообще», как о тотальной совокупности всего, что обозначается словом «культура», поскольку параметры ее разных сегментов существенно различаются между собой. Например, насколько можно говорить о культуре социальной и культуре символической как о едином явлении? Социальная культура в первую очередь способствует сочиальной интеграции, осуществлению человеческой жизнедеятельности в коллективных формах. А символическая культура в основном отображает наблюдаемую или представляемую реальность в виде художественных и религиозных образов, а проблем социальной интеграции непосредственно не касается. Невольно возникает мысль о том, что речь идет о двух автономных сферах человеческой деятельности, лишь случайно называемых одним словом «культура».

Но все же я полагаю, что оба эти феномена являются частью единой культуры, в конечном счете обеспечивающими социальную интеграцию, но разными способами. Социальная культура (этническая, сословно-классовая, профессиональная, политическая, национальная) преследует цель непосредственного обеспечения коллективного образа жизни через его организационные формы, поведенческие стереотипы, обычаи, нравы, законы, технологии и т. п. А символическая культура (в первую очередь художественная, включая литературу, и религиозная (мифологическая)) обеспечивает эту интеграцию опосредованно, создавая благоприятную психологическую атмо- 
сферу (ауру), при которой коллективные формы жизнедеятельности воспринимаются как наиболее правильные. Не будем забывать, что в большинстве художественных и практически во всех религиозных текстах коллективные формы деятельности людей, их групповые интересы и потребности противопоставляются индивидуальным и прославляются как более верные, эффективные, богоугодные. На раннем этапе истории искусство и религия являлись наиболее последовательными учителями и пропагандистами преимуществ коллективного начала над индивидуальным и постоянно осуждали персонажей, совершавших действия, нарушающие конструктивное взаимодействие между людьми (на всех уровнях, вплоть до семейного). Хотя, как уже говорилось, целей социальной интеграции они непосредственно не преследуют.

Эта доминанта коллективных форм жизнедеятельности была унаследована людьми от приматов, ведущих групповой образ жизни (в стаях), и сохранялась в первобытной культуре и в большой мере в культуре аграрной эпохи. Но со времени итальянского Ренессанса индивидуальное начало в человеке постепенно «реабилитируется» как эффективная мотивация его социальной активности.

Этот процесс начался прежде всего в искусстве. Средневековое искусство избегало индивидуальной авторской выразительности в изображениях и по византийской традиции идентифицировало изображаемых персонажей по каким-то внешним атрибутам (одежде, позам, предметам в руках, внешнему окружению и пр.), а не по чертам лиц. В искусстве Ренессанса рождается интерес к человеческой индивидуальности, что находит выражение, с одной стороны, в развитии персональных авторских проявлений в творчестве самого художника (писателя) - в узнаваемом авторском стиле, а с другой - во все большем внимании к индивидуальным дичностным чертам персонажей художественных произведений. Искусство эпохи Ренессанса называют «открытием человека», установлением его самоценности и критериальной значимости (см., напр.: Баткин, 1995; Брагина, 2002). Подобную художественную установку поддерживала и гуманистическая философия того времени. Отдельный человек, а не коллектив или община обозначался мерой всех вещей. Индивидуализащия в обоих названных аспектах стала основной парадигмой развития искусства всех последующих эпох. Именно поэтому искусство, бывшее ранее естественной компонентой религиозного культа, начало все больше отдаляться от религии, опиравшейся на совершенно иную иерархию ценностей, где община была важнее отдельного человека.

И в социальной жизни начали постепенно проявляться признаки наступающей индивидуализации культуры. Первым шагом было появление дуэли как метода защиты своего личного достоинства с оружием в руках. Ауэли возникли в ренессансной Италии в XIV-XV вв. и в XVI-XVII вв. постепенно распространились по Европе. Вспомним трех мушкетеров из романа А. Аюма, для которых постоянные дуэли были просто образом их жизни. Речь идет именно о защите дичного (индивидуального) достоинства, потому что в Средние века поединки были дибо рыцарскими турнирами (т. е. чисто спортивными состязаниями), либо защищали интересы сюзерена, честь рода (фамилии), но не отдельной личности сражающегося. Такое ощущение собственного достоинства родилось именно в ренессансной Италии вместе с художественным открытием человека.

В России дуэли вошли в образ жизни дворянства и стали распространенным явлением сравнительно поздно - в начале XIX в. Еще в XVIII в. дворянин чувствовал себя «холопом государевым» и о личном достоинстве не помышлял. Эту функцию замещала родовая знатность. Потребовались длительное царствование Екатерины II, ее 
просвещенный абсолютизм и большая личная тактичность и толерантность, контрастный к этому произвол Павла I, патриотический подъем эпохи Наполеоновских войн и пр., чтобы в русском дворянстве проснулось ощущение собственного человеческого достоинства (Кацура, 2006). Когда А. С. Пушкин в «Капитанской дочке» описывает дуэль Гринева со Швабриным, это можно считать авторской вольностью, перенесением в XVIII в. нравов пушкинских времен. В 1773 г. (год начала Пугачевского восстания) дуэли в России были большой редкостью. Индивидуализация личности еще не зашла так далеко.

Аругой пример - становление системы идентификации личности. Этот процесс растянулся на многие века. В уже упомянутых «Трех мушкетерах» все герои обращаются друг к другу только по фамилии (д’Артаньян, де Тревиль, Рошфор и др.) или по псевдонимам (Атос, Портос, Арамис). По личным именам называются только члены царствующего дома (Июдовик XIII, Анна Австрийская). Исторического д’Артаньяна звали Шарль, но на страницах романа это имя не приводится. Иногда это запутывало даже такого знатока истории, как А. Аюма. В конце трилогии о мушкетерах он производит д’Артаньяна в маршалы Франции. Аействительно, при Аюдовике XIV был маршал д’Артаньян, но не герой «Трех мушкетеров» Шарль д’Артаньян, а его кузен граф Пьер де Монтескью д’Артаньян. Однако в XVII в. индивидуализация личности в имени была еще столь нечеткой, что Аюма не разобрался в том, какой д’Артаньян имелся в виду.

Крестьяне, наоборот, фамилий не имели, а звались по имени и прозвищу. Рабам фамилии не положены. Русские крестьяне только после освобождения в 1861 г. получили индивидуальные фамилии, придумываемые чиновниками, ведшими записи. В целом в XVIII-XIX вв. начала выстраиваться современная система идентификации личности по имени и фамилии (в России еще и по отчеству), которая тоже далека от совершенства, но более или менее операциональна.

Если в эпоху Ренессанса искусство и литература только признавали индивидуальность как отличительную черту человека (преимущественно внешнюю), то начиная с XVIII-XIX вв. художественное творчество стало прославлять ее как особую ценность (не только внешнюю, но и внутреннюю, личностную). Родился психологический роман, фактически сосредоточенный именно на этом. Портретная живопись превратилась в один из основных жанров искусства. Аичностная индивидуальность стала признаком аристократизма.

В течение XX в. и особенно с переходом к постиндустриальной стадии развития процесс социальной индивидуализации заметно усилился, охватывая род занятий, образ жизни, увлечения, развлечения и т. п. Человек начал противопоставлять себя обществу. Этому вопросу уже посвящены несколько капитальных исследований (см.: Бауман, 2002; Элиас, 2001). Показательно, что в целом ряде областей труда человека, особенно связанных с интеллектуальным творчеством, индивидуальная работа стала более эффективной, нежели коллективная. Сейчас еще трудно системно осмыслить эту тенденцию в организации деятельности, но на интуитивном уровне расширение сферы индивидуального и сокращение сферы коллективного труда ощущается вполне четко. Аа и экономически индивидуальный труд оплачивается выше.

\section{БАИАНС МЕЖАУ КОААЕКТИВНОЙ И ИНАИВИАУААЬНОЙ КУАБТУРАМИ. УРОВЕНЬ СВОБОАЫ КАК ОАИЦЕТВОРЕНИЕ ЭТОГО БАААНСА}

Означает ли это, что изначальная установка культуры на поддержание коллективных форм жизнедеятельности, дающих больший шанс на выживание в противовес ме- 
нее устойчивым индивидуальным формам, заканчивает свое историческое существование и постепенно вытесняется индивидуализмом? В практической сфере социальной активности значимость индивидуальных форм уже не уступает значимости коллективных форм. Процесс глобализации в большой мере выражен в том, что коллективные «грязные производства» вытесняются в страны третьего мира (Китай, Мексику), а постиндустриальный «первый мир» превращается преимущественно в зону интеллектуального труда. В идеологии это выглядит как противостояние системы коллективных ценностей (например, в форме социализма) ценностям индивидуальным (либерализму), что выражено наиболее наглядно.

Но мне представляется, что речь не идет о вытеснении одного другим. Имеет место очень сложный и противоречивый процесс утверждения индивидуального начала в социальной жизни как столь же значимого, что и коллективное, и поиска баланса между ними. Наглядным выражением этого служат представления о свободе. Свобода - это один из аспектов соотношения коллективного и индивидуального начал в социальной жизни общества. Уровень свободы индексирует уровень разрешенной (легализованной) индивидуализации культуры. Потребность человека в свободе - это объективная потребность в постепенном расширении зоны индивидуализации в деятельности (об этом см., напр.: Бауман, 2006). В разные эпохи и в разных областях жизни актуальными были разные сегменты свободы. Например, в Европе начала нового времени наиболее актуальной была потребность в интеллектуальной свободе от вероучебных установок католической церкви. В XIX-XX вв. особую актуальность обрела потребность в свободе от социального контроля со стороны политической власти. В художественной культуре с рубежа XIX-XX вв. сложилось стремление к свободе художественной формы от стилевой регламентации господствующей идеологии и т. п.

Безусловно, всем понятно, что свобода не означает полной независимости индивида от общества (это уже анархия), а выражает определенное психологически комфортное сочетание элементов зависимости и независимости индивида от его социальной среды. Вот этот психологически комфортный баланс (компромисс) и должна обеспечить культура. Проблема соотношения свободы и культуры неоднократно рассматривалась философами (см., напр.: Берлин, 2001, 19-43; Межуев, 2009, 5-16; Пелипенко, 2014). Но ими мало внимания уделялось ракурсу понимания свободы как исторического баланса феноменов коллективной и индивидуальной культуры. А этот ракурс позволяет глубже понять свободу как явление культуры и потребность человека в свободе как отражение исторического роста индивидуальной культуры и сокращения зоны влияния культуры коллективной. Тем не менее этот рост направлен не на элиминацию коллективного начала, а только на более комфортный баланс с ним.

Соответственно, несвобода - это отсутствие психологически комфортного соотношения между зависимостью и независимостью индивида от общества. Научная проблема здесь видится в том, что характеристики комфортности очень подвижны, меняются от эпохи к эпохе, различаются у разных социальных страт, а порой и у отдельных личностей и т. п. Рассчитать их научно практически невозможно.

Так или иначе, но параметры свободы (политической, идеологической, информационной и др.) могут служить показателем реальной комфортности сочетания коллективной и индивидуальной культуры в обществе (см. об этом также: Флиер, 2006, 2017). Обычно этот уровень определяется по господствующей идеологии, которая, как правило, соответствует политической практике. Но мы знаем и исключения из этого правила. Например, тоталитарной идеологии режима генералиссимуса Ф. Франко 
в Испании сопутствовала сравнительно умеренная по своей репрессивности внутренняя политика. Политическая модель современной России имеет типологически схожие черты. Однако подобные исключения не отменяют правила. Тип господствующей идеологии - либеральной, этатистской, социалистической и т. п. - обычно соответствует разрешенному уровню свободы, т. е. масштабу допустимой в том или ином обществе индивидуализации культуры. Идеология - это в большой мере и есть официально господствующая в обществе культура в ее политической интерпретации. Направленность идеологии, уровень личной свободы и черты господствующей культуры суммарно составляют сложный, многоаспектный комплекс состояния общественного сознания, отражающего доминантные ценностные ориентации, характерные для того или иного общества.

Из сказанного вовсе не следует, что индивидуальные формы жизнедеятельности это прогресс, а коллективные - регресс (как полагают либералы) или наоборот (как полагают социалисты и консерваторы). И то, и другое имеет свои плюсы и свои минусы. Все ситуативно. Книгу писать лучше одному, а строить дом - коллективом. В большой мере именно этим определяется либеральная ориентация интеллектуалов и социалистическая ориентация рабочего класса. Вместе с тем если в первобытную эпоху насчитывалось весьма ограниченное число трудовых акций, в которых индивидуальное исполнение было эффективней коллективного, то ныне в постиндустриальном обществе число сфер деятельности обоих видов примерно сопоставимо. А это значит, что историческое социальное развитие идет по линии сокращения форм жизнедеятельности, в которых требуется объединение усилий многих людей, и расширения сфер, в которых требуются индивидуальные интеллектуальные усилия. Такова наблюдаемая тенденция углубления специализации, определяющая динамику исторического развития, выявленная еще в конце XIX в. (Аюркгейм, 1991).

\section{БАИАНС КАК ПРОТИВОРЕЧИВЫЙ ПРОЦЕСС}

Впрочем, в современной культуре наблюдаются и явления, противостоящие процессам индивидуализации. Это в первую очередь развитие системы коммуникации «каждого с каждым», связанное с прогрессом в области информационных технологий и особенно с Интернетом. Развитие контактов массовой коммуникации ведет к выравниванию интерпретационного разнообразия и стандартизации многих аспектов мироощущения и всего массового сознания общества в целом. Такую же роль играет и развитие СМИ, которые независимо от воли тех или иных журналистов также активно способствуют стандартизации сознания общества, особенно в интерпретации мировых событий. Этим продуктивно пользуются государственные идеологические машины во всех странах. Все это представляется вполне нормальными процессами функционирования культуры, в которой система сдержек и противовесов во все времена была достаточно развита и не допускала чрезмерного доминирования какихто тенденций.

Итак, каким образом современная культура связывает коллективное и индивидуальное начала в социальной жизни? Как поддерживается психологически комфортный баланс между двумя составляющими современной культуры? Во-первых, демонстрацией их равной значимости. В различных произведениях искусства это показано по-разному, но в целом нельзя сказать, что в сегодняшних искусстве и литературе преобладает назойливая апология коллективизма (как в советском искусстве) или индивидуализма. Во-вторых, их взаимным уравновешиванием. Например, демократия - 
это политическое торжество коллективизма (воли большинства), а политический либерализм, мультикультурализм, толерантность - это апология индивидуализма, которые компенсируют друг друга. В современной жизни в Европе и Америке воля большинства сочетается с гарантиями прав меньшинства, социальная поддержка бедных - с налоговыми льготами предпринимателей, местные обычаи - со свободными культурными проявлениями приезжих и т. п. В-третьих, политическим равноправием всех идеологий, даже человеконенавистнических, но непосредственно не призывающих к насилию. Человек может придерживаться любых политических взглядов, не совершая никаких насильственных действий. В-четвертых, социальная самореализация человека зависит преимущественно от его персональной конкурентоспособности. Высококонкурентоспособные люди самореализуются в основном в сфере индивидуальной трудовой деятельности, менее конкурентоспособные, как правило, в системе коллективного труда. В-пятых, равной доступностью всех досугово-развлекательных программ (в дистантной форме, разумеется). Человек может слушать любую музыку, смотреть любой фильм, читать любую книгу и т. п. И еще множество пунктов можно перечислить в этой связи. Но главное - это поддержание уверенности людей в том, что помимо государства они находятся под защитой общества, и ситуативно либо одно, либо другое помогут всем и каждому в отдельности. В современном постиндустриальном мире человек по своей ценности равен коллективу, и наоборот. Это основа современного баланса между коллективной и индивидуальной культурами.

Следует сказать, что устойчивость этого баланса относительна. Ведь общество состоит из самых разных людей. Кто-то удовлетворен объемом существующей свободы, кто-то считает его недостаточным, а кто-то чрезмерным. И соотношение влияния этих групп постоянно меняется в зависимости от сочетания различных внешних и внутренних факторов. Иногда недовольство вырастает до революционной ситуации. Хотя современные постиндустриальные государства умеют гибко реагировать на накопление социального недовольства и снимать его теми или иными поворотами своей внутренней политики.

\section{ЗАКАЮЧЕНИЕ}

Конечно, еще не все общества на планете достигли постиндустриальной стадии; это прерогатива лишь наиболее развитых стран, преимущественно западноевропейских и североамериканских. Но такая перспектива в принципе открыта для всех. Такова современная историческая тенденция социального развития, сохраняющаяся, несмотря на локальные отступления от нее (взлеты правого популизма, консерватизма, вульгарного патриотизма и пр.).

Во всем этом проявляются достаточно сложные и противоречивые социальные процессы, протекающие в каждом обществе. И еще никем не доказана долговечность описанной направленности развития. Вполне возможно, что сегодня преобладает одна тенденция, а завтра (через 100 лет) возобладает иная. Но потребность человека в психологически комфортном балансе между коллективной и индивидуальной культурой останется в любой ситуации, и наблюдаемый уровень личной свободы человека является практическим выражением этого компромисса.

\section{СПИСОК АИТЕРАТУРЫ}

Баткин, А. М. (1995) Итальянское возрождение: Проблемы и люди. М. : ИзА-во РГГУ. 448 с. Бауман, 3. (2002) Индивидуализированное общество : пер. с англ. М. : Аогос. 390 с. 
Бауман, 3. (2006) Свобода : пер. с англ. М. : Новое издательство. 132 с.

Берлин, И. (2001) Аве концепции свободы // Берлин, И. Философия свободы. Европа. М. : Новое литературное обозрение. 448 с. С. 19-43.

Брагина, А. М. (2002) Итальянский гуманизм эпохи Возрождения. Идеалы и практика культуры. М. : ИзА-во МГУ. 384 с.

Аюркгейм, Э. (1991) О разделении общественного труда. Метод социологии. М. : Наука. 575 с.

Кацура, А. В. (2006) Ауэль в истории России. М. : Радуга. 392 с.

Межуев, В. М. (2009) Свобода как ценность // Альтернативы. № 4. С. 5-16.

Пелипенко, А. А. (2014) Свобода в культуре [Электронный ресурс]// Культура культуры. № 1. URL: http:// cult-cult.ru/a-a-pelipenko-svoboda-v-kulitur (дата обращения: 12.01.2017).

Флиер, А. Я. (2006) Культура как репрессия. М. : Аиаграмма. 320 с.

Флиер, А. Я. (2017) Аве роли человека в «спектакле культуры» // Знание. Понимание. Умение. № 1. С. 123-131. DOI: 10.17805/zpu.2017.1.8

Элиас, Н. (2001) Общество индивидов. М. : Праксис. 336 с.

Аата поступления: 12.01.2017 2.

\author{
UNSTABLE BALANCE BETWEEN COLLECTIVE AND INDIVIDUAL BEGINNINGS \\ IN CULTURE. FREEDOM AS AN INDICATOR OF BALANCE \\ A. YA. FLIER \\ RUSSIAN SCIENTIFIC RESEARCH INSTITUTE FOR CULTURAL \\ and Natural HeRItage named after D. LiKHACHEV
}

The article is devoted to the interaction and balance of collective and individual forms of living and the respective cultures, historical trends of this process and its connection with the formation and development of the concepts of freedom, with the dominant forms of ideology.

The article substantiates the unity of goals of the social and symbolic segments of culture, which provide social integration, both directly and indirectly. Initially, culture was focused on the apologetics of the collective principle of living. The «rehabilitation» of the individual principle in culture begins with the Italian Renaissance art. In social life the process of individualization began with the emergence of the duel as a means of protection of personal dignity, and as system of human identification by name and surname. The modern era is characterized by a high level of development of individual culture and the reduction of the scope of collective culture.

But we are not talking about the displacement of one by the other, but only about the balance of both. This balance is expressed by the extent of freedom. Freedom is the expression of a psychologically comfortable balance of collective and individual principles in culture. The expansion of freedom is the strengthening the individual principle. It is most clearly expressed in the dominant ideology. This balance is historically unstable and is associated with a predominance of a particular socio-political segment of society. But in any case, the society needs to maintain a psychologically comfortable balance between collective and individual cultures.

Keywords: culture; freedom; collective culture; individual culture; ideology; specialization

\title{
REFERENCES
}

Batkin, L. M. (1995) Ital'ianskoe vozrozhdenie: Problemy i liudi. Moscow, RGGU Publ. 448 p. (In Russ.). Russ.).

Bauman, Z. (2002) Individualizirovannoe obshchestvo, transl. by Engl. Moscow, Logos. 390 p. (In

Bauman, Z. (2006) Svoboda, transl. by Engl. Moscow, Novoe izdatel'stvo. 132 p. (In Russ.).

Berlin, I. (2001) Dve kontseptsii svobody. In: Berlin, I. Filosofiia svobody. Evropa. Moscow, Novoe literaturnoe obozrenie. 448 p. Pp. 19-43. (In Russ.).

Bragina, L. M. (2002) Ital'ianskii gumanizm epokbi Vozrozbdeniia. Idealy i praktika kul'tury. Moscow, MGU Publ. 384 p. (In Russ.). 
Durkheim, E. (1991) O razdelenii obshchestvennogo truda. Metod sotsiologii. Moscow, Nauka. 575 p. (In Russ.).

Katsura, A. V. (2006) Duel' v istorii Rossii. Moscow, Raduga. 392 p. (In Russ.).

Mezhuev, V. M. (2009) Svoboda kak tsennost'. Al'ternativy, no. 4, pp. 5-16. (In Russ.).

Pelipenko, A. A. (2014) Svoboda v kul'ture. Kul'tura kul'tury, no. 1 [online] Available at: http://cult-cult.ru/a-a-pelipenko-svoboda-v-kulitur (access date: 12.01.2017). (In Russ.).

Flier, A. Ia. (2006) Kul'tura kak repressiia. Moscow, Diagramma. 320 p. (In Russ.).

Flier, A. Ia. (2017) Dve roli cheloveka v «spektakle kul'tury». Znanie. Ponimanie. Umenie, no. 1, pp. 123-131. DOI: 10.17805/zpu.2017.1.8 (In Russ.).

Elias, N. (2001) Obshchestvo individov. Moscow, Praksis. 336 p. (In Russ.).

Submission date: 12.01.2017.

Флиер Андрей Яковлевич - доктор философских наук, профессор, главный научный сотрудник Российского научно-исследовательского института культурного и природного наследия им. А. С. Аихачева. Адрес: 129366, Россия, г. Москва, ул. Космонавтов, д. 2. Тел.: +7 (495) 686-13-19. Эл. aspec: andrey.flier@yandex.ru

Flier Andrei Yakovlevich, Doctor of Philosophy, Professor, Chief Research Scientist, Russian Scientific Research Institute for Cultural and Natural Heritage named after D. Likhachev. Postal address: 2, Kosmonavtov St., Moscow, Russian Federation 129366. Tel.: +7 (495) 686-13-19. E-mail: andrey.flier@yandex.ru 